\title{
SOMATOSENSORY CORTICAL-EVOKED RESPONSES AFTER FELINE EXPERIMENTAL SPINAL CORD INJURY*
}

\author{
By Philip A. Singer, M.D., Leon D. Prockop, M.D. and \\ Douglas K. Anderson, Ph.D. \\ Research Service, Veterans Administration Hospital, Tampa, Florida, and the Neurology \\ Section, Department of Internal Medicine, University of South Florida, Florida, U.S.A.
}

Abstract. Somatosensory cortical-evoked responses and clinical function were followed in cats for up to 4 weeks after spinal cord compression injury. Despite abolition of cortical responses for from 3 to I9 days after injury, good functional recovery occurred.

Key words: Cortical-evoked responses; spinal injuries.

\section{Introduction}

CORTICAL responses to somatosensory stimulation have previously been studied as an index of spinal cord injury (SCI) in experimental animals and man. Donaghy and Numoto (1969) used an impact injury to correlate functional recovery and cortical-evoked potentials (CEPs) in dogs. They found that the cortical response was abolished immediately after injury. On the basis of further observations they concluded that if the CEP recovered within 4 hours of SCI, the prognosis for functional recovery was good. De la Torre et al. (1975) used a similar injury in dogs and concluded that the absence of cortical responses 3 hours after injury was always associated with permanent paraplegia. Martin and Bloedel (1973) and Pudiphorn et al. (1975) used inflation of a Fogarty catheter in the spinal canal to produce SCI. They found that if CEPs returned within 3 hours of spinal cord injury, their animals went on to functional recovery.

The pathology (D'Angelo et al., 1973) after impact injury also appears to correlate with cortical-evoked potentials. Immediate return of responses after injury was seen in cats exhibiting only petechial haemorrhages on post-mortem examination after sacrifice. However, animals with central cavitation and posterior column destruction showed no recovery of responses during the 4-hour period of observation.

Thus, the available evidence indicates that recovery of CEPs within 4 hours after spinal cord injury is correlated with a good prognosis for functional recovery.

The present study was undertaken as part of a multidisciplinary effort to study SCI. The cerebrospinal fluid (Anderson et al., 1976) and pathologic (Means \& Anderson, 1975) changes using this model of spinal cord injury have already been reported. The electrophysiologic studies were intended primarily to determine if there is a correlation between CEP recovery and functional recovery using the compression model of SCI described below.

\section{Methods}

Seven adult female mongrel cats weighing 2.5 and $3.5 \mathrm{~kg}$ were used. Animals were anaesthetised with nembutal $40 \mathrm{mg} / \mathrm{kg}$ and placed in a stereotaxic frame. An

Address for offprints: Dr P. A. Singer, Kansas City Veterans Administration Hospital, 480 I Linwood, Kansas, Missouri, 64128, U.S.A.

* This work was supported in part by V.A. Project 039I-OI. 
endotracheal cannula was insterted and a femoral arterial and venous catheter were used to monitor blood pressure and give supplemental nembutal as needed. The temperature was maintained at $38^{\circ} \mathrm{C}$ with a heating pad.

The calvarium was exposed using standard operative techniques under aseptic conditions. Electrodes consisting of screws were placed through the bone in contact with the dural surface. The active electrode was placed $3 \mathrm{~mm}$ lateral to the sagittal suture and $2 \mathrm{~mm}$ anterior to the coronal suture. Later pathologic examination showed this to be over the somatosensory cortex. An indifferent electrode was placed on the occipital ridge and a ground in the opposite frontal sinus. The electrodes were connected to an Augate 8059-2G6 plug. The exposed portions of the electrodes were covered with dental acrylic and the plug cemented to the skull with the same material. The wound was then closed.

The method of producing SCI as described by Anderson et al. (1976) was followed. Laminectomy was performed at the T2 level. A I70-g weight was applied to the exposed, intact dura for 5 min during which time the animals were paralysed with succinyl choline and artificially ventilated. The wound was closed and the animal given 100,000 units of procaine penicillin and subcutaneous ringers lactate $\mathrm{ro} \mathrm{cc} / \mathrm{kg}$.

Cortical responses were amplified using a Grass P-I5 AC preamplifier and a Textronix $5 \mathrm{Ar} 8 \mathrm{~N}$ dual trace amplifier. They were displayed on a Textonix R5I03 N oscilloscope and stored on a Tandberg 4-channel FM tape recorder using a tape synchronisation unit. Subsequently, 64 conservative traces were averaged using a Hewlett Packard average response computer. Stimuli consisted of 30-40 $\mathrm{V}, \mathrm{O} \cdot \mathrm{I}$ msec square-wave pulses generated by a Grass $\mathrm{S}_{44}$ stimulator and an SI U5 stimulus isolation unit. These were delivered to the contralateral foreleg and hindleg by stainless steel needle electrodes. The cathode was inserted into the footpad; the anode percutaneously dorsal to the metacarpo-phalangeal joint.

Responses were recorded to both contralateral forelimb and hindlimb stimulation. The responses to forelimb stimulation served as a control for anaesthesia, electrode integrity and cortical responsiveness. Responses were studied before laminectomy, under succinyl choline, immediately after injury, at I, 4, 6, and 24 hours and every 3 to 6 days for up to 4 weeks. In preliminary studies, follow-up responses to hindleg stimulation were recorded in awake animals. However, because the stimuli appeared to produce discomfort, the animals were subsequently anaesthetised briefly with thioamylol sodium $30 \mathrm{mg}$ intravenously during recording.

Motor performance was rated by the following scale as used by De la Torre et al. (I975): 0 = flaccid paraplegia; I = some muscle tone; $2=$ reflex standing; $3=$ walking with deficit; $4=$ walking, running with deficit; $5=$ normal full recovery.

In addition, response to nocioceptive stimulation in the hindlimbs was tested. The presence of a sensory level was noted. Bladder function observed by the presence of spontaneous voiding and the presence of bladder distention.

\section{Results}

Clinical Recovery

In four animals paraplegia was evident upon recovery from anaesthesia. Typically, these animals had reflex withdrawal to noxious stimulation and crossed extension reflexes. Stimulation below the level of the lesion, however, was ignored. Tone was either normal or slightly increased. There was no spontaneous 


\section{TABLE I}

Results of cortical-evoked responses and functional recovery. Animals I-5 were subjected to spinal cord injury (SCI). Animals 6 and 7 had only laminectomy

\begin{tabular}{cccc}
\hline Animal & $\begin{array}{c}\text { Initial response } \\
\text { (first 24 hours) }\end{array}$ & $\begin{array}{c}\text { Response recovered } \\
\text { (days) }\end{array}$ & $\begin{array}{c}\text { Walking } \\
\text { (days) }\end{array}$ \\
\hline SCI & $(-)$ & $2 \mathrm{I}$ & \\
I & $(-)$ & 9 & 19 \\
2 & $(-)$ & $\mathrm{I} 2$ & $\mathrm{IO}$ \\
3 & $(-)$ & $9^{\star}$ & 8 \\
4 & $(-)$ & & No recovery \\
5 & $(+)$ & Immediate & Immediate \\
Control & $(+)$ & Immediate & Immediate \\
6 & $\star$ Long latency 40 msec response. \\
7 & &
\end{tabular}

voiding for the first 3 weeks and manual compression of the bladder was necessary to avoid bladder distension. Subsequently, spontaneous voiding recovered. Constipation was evident during the first 3 to 6 days. All four of these animals (Table I, animals I-4) recovered normal walking 8 to I9 days post-SCI. Recovery occurred gradually. There was a period of increased tone with some spontaneous stepping motions which progressed to standing if the animal was first supported. Subsequently, spontaneous walking occurred but gait was ataxic because of frequent hindlimb collapse. There was then gradual improvement to normal walking. Two of the animals which were followed for as long as 4 weeks recovered to completely normal walking and running.

Laminectomy without SCI was performed in two animals. They walked normally immediately upon recovery from anaesthesia (Table I, animals 6 and 7) and are included as controls. One animal (Table I, animal 5), paraplegic after SCI, exhibited improvement in bladder function and increased muscle tone, but remained paraplegic during the 22-day follow-up period.

\section{Electrophysiologic Responses}

The pre-injury primary responses typically consisted of a small positive deflection followed immediately by a larger negative deflection. The latencies were 6-8 $\mathrm{msec}$ for the contralateral forelimb responses and 8-10 $\mathrm{msec}$ for the contralateral hindlimb responses (Fig. I). The amplitude varied between 5 and I 5 uv. They were very constant under nembutal anaesthesia. The amplitude of the control contralateral forelimb response was 20-30 uv higher in the unanaesthetised animal or under thiamylal anaesthesia than with nembutal anaesthesia, but the responses were less constant. Muscle artifact is excluded since the responses were unchanged by succinyl choline.

Responses in all animals rendered paraplegic were abolished during the first 3-I9 days (Figs. 2, 3, 4) following SCI. In particular, no response could be recorded during the first 24 hours following the injury. Recovery of a small (5-IO uv) primary response occurred from 3 to 2 I days following SCI. In three 


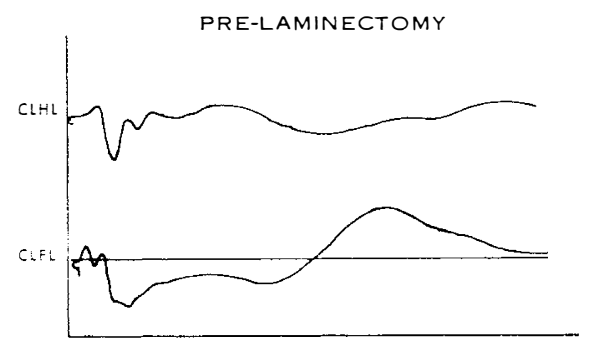

AFTER SUCCINYL CHOLINE

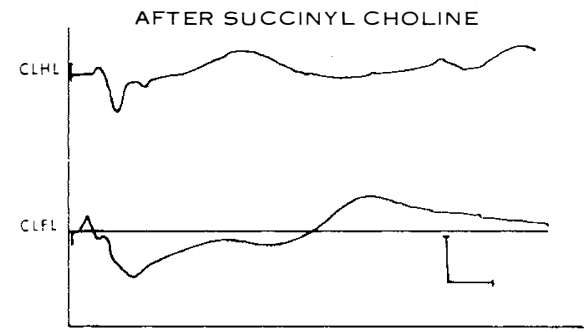

FIG. I

Somatosensory cortex response to contralateral hindlimb (CLHL) and contralateral forelimb (CLFL) under nembutal anaesthesia before laminectomy and after laminectomy with succinyl choline. Scale equals Io uv, $20 \mathrm{msec}$. Animal I.

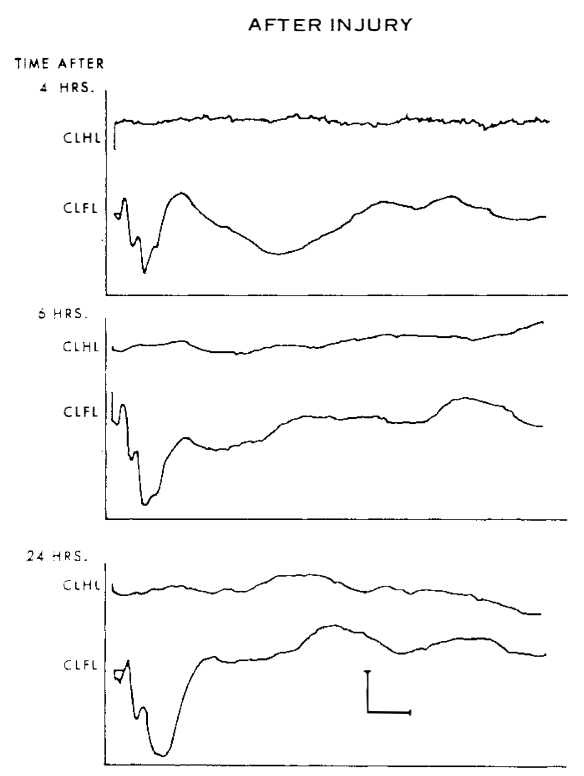

FIG. 3

Somatosensory cortex response to contralateral hindlimb (CLHL) and contralateral forelimb (CLFL) stimulation 4, 6, and 24 hours after injury. Light nembutal anaesthesia. Scale equals Io uv, $20 \mathrm{msec}$. Animal $\mathrm{I}$.

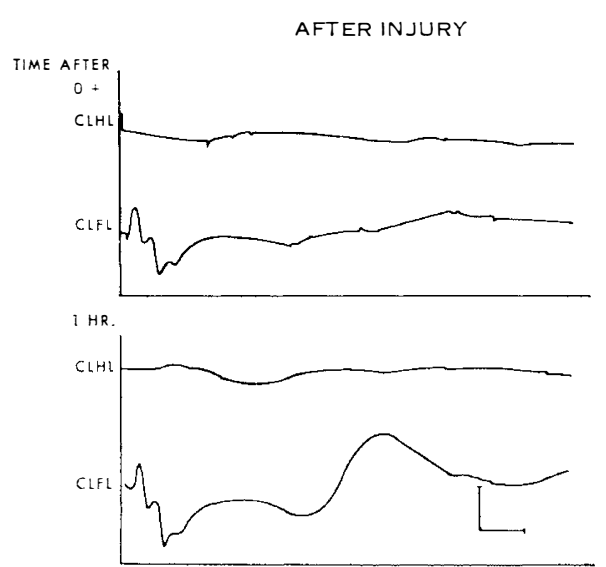

FIG. 2

Somatosensory cortex response to contralateral hindlimb (CLHL) and contralateral forelimb (CLFL) stimulation immediately after and I hour after injury. Nembutal anaesthesia. Scale equals Io uv, $20 \mathrm{msec}$. Animal I.

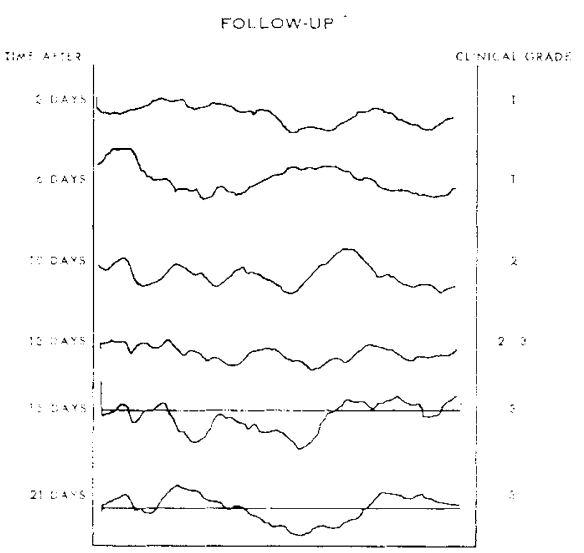

FIG. 4

Somatosensory cortex response to contralateral hindlimb (CLHL) stimulation. Numbers on left indicate number of days after injury, those on right the clinical grade of motor performance (see Methods). Thiamylal anaesthesia. Scale equals Io uv, $20 \mathrm{msec}$. Animal I. 
animals the response occurred at the same time as functional recovery. In the animal which remained paraplegic (Table I, animal 5), no primary response was seen after injury. However, a consistent response with a latency of $40 \mathrm{msec}$ did occur 9 days post-injury. The control animals (Table I, animals 6 and 7) had normal responses throughout.

\section{Discussion}

Four of the animals presented had good functional recovery despite the absence of CEPs to contralateral hindlimb stimulation for from 3 to I 9 days after SCI. The implication of this data is that good functional recovery may occur even though CEPs are absent in the first hours or days after injury. This is at variance with the conclusions of other authors.

Donaghy and Numoto (1969) used an impact injury to produce SCI. A $20-\mathrm{g}$ weight was dropped from a $30-\mathrm{cm}$ height on to the spinal cord of dogs. They followed cortical-evoked potentials (CEPs) for 4 hours after the acute injury and restudied the animals 8 weeks later. Seven of their animals showed good clinical recovery at the end of 8 weeks. Five of these animals had recovery of CEPs 4 hours after the injury and all had responses at 8 weeks. Only two of their animals with no CEPs at 4 hours attained walking at 8 weeks following SCI. They concluded that there was a good correlation between return of CEPs within 4 hours of injury and subsequent clinical recovery.

De la Torre et al. (1975) used a similar impact model in dogs with a $20-\mathrm{g}$ weight dropped from $25 \mathrm{~cm}$. They monitored cortical responses for 48 hours following injury. When the CEP was absent 3 hours after injury, there was no clinical recovery. However, if the response was present 3 hours after injury, recovery occurred in 90 per cent of their animals.

Martin and Bloedel (1973) used graded inflation of a balloon catheter in the spinal canal to produce SCI in cats. They found that with minimal inflation of the catheter, CEPs were present immediately after injury and recovery occurred. With moderate inflation of the balloon, CEPs returned within 3 hours and all animals were able to walk within 6 weeks after injury. With more severe injury CEPs were either absent or were present at some time within the first 3 hours but later disappeared. None of these animals recovered.

Pudiphorn et al. (1975) also used inflation of a Fogarty catheter as an injury model and found that animals with no recovery of CEPs 6 hours after injury remained paraplegic. In both of these latter studies, the balloon inflation was instantaneous, thus probably producing an impact injury.

The difference between the present study and those detailed above may be the injury model used. The pathophysiology of compression injury may be different from impact injury. Tarlov (I957) postulated that mechanical disruption of fibre tracts was responsible for electrophysiologic conduction block. However, Croft et al. (1972) observed rapid return of CEPs after compression. They concluded that ischaemia may be a greater factor in compression injury. A more severe initial compression could still result in functional recovery if mechanical disruption of fibre tracts has not occurred.

Theoretical data supports the use of CEPs as an indicator of the electrophysiologic integrity of the spinal cord. In cats, Morin (1955) has shown that ventrolateral tracts as well as the dorsal columns are necessary for CEPs. The measurement of these primarily afferent responses then probably indicates the electrophysiologic integrity of the lateral spinal cord including the corticospinal tracts. Loss of CEPs after spinal cord injury in the cat probably indirectly reflects 
the functional state of motor as well as afferent tracts. In man, however, sensation mediated by the dorsal columns is more closely correlated with cortical responses (Gilbin, 1964).

Most studies then, support the conclusion that recovery of CEPs within 4 to 6 hours after SCI indicates eventual good functional recovery. In the animals presented here, CEPs were absent for up to I9 days following SCI with subsequent functional recovery. The absence of cortical responses may not be an absolute indicator of permanent paraplegia. This may be particularly germaine when compression injury is involved.

\section{SUMMARY}

Somatosensory cortical-evoked responses were studied in seven adult cats following spinal cord injury with I70-g weight applied to the exposed, intact dura. CEPs were absent up to I9 days with subsequent functional recovery. The absence of CEP may not be an absolute indicator of permanent paraplegia.

\section{RÉSUMÉ}

Les réactions somatosensorielles évoquées par le cortex ont été étudiées sur 7 chats adultes après lésion de la moelle épinière par application d'un poids de $170 \mathrm{~g}$ sur la dura intacte exposée. Les CEP étaient absents pendant 19 jours maximum avec rétablissement fonctionnel par la suite. Il se peut que l'absence de CEP ne constitue pas une indication absolue d'une paraplégie permanente.

\section{ZUSAMMENFASSUNG}

Somatosensorische Reaktionen, kortical ausgelöst, wurden in 7 Katzen untersucht nach Rückenmarksverletzung mithels $170 \mathrm{~g}$ Gewichtstrauma auf die intakte Dura. CEP war negativ bis zu I9 Tagen mit folgender funktioneller Wiederherstellung. Die Abwesenheit der CEP ist nicht ein absoluter Indikator für eine Paraplegia.

\section{REFERENCES}

Anderson, D. K., Prockop, L. D., Means, E. D. \& Hartley, L. E. (I976). Cerebrospinal fluid lactate and electrolyte levels following experimental spinal cord injury. $\mathcal{F}$. Neurosurg. 44, 715.

Croft, T. J., Brodkey, J. S. \& Nulsen, F. E. (1972). Reversible spinal cord trauma: A model for electrical monitoring of spinal cord function. f. Neurosurg. 39, 402.

D'ANGelo, C. M., VAN Gilder, J. C. \& TAub, A. (I973). Evoked cortical potentials in experimental spinal cord trauma. F. Neurosurg. 38, 332.

de la Torre, J. C., Johnson, C. M., Goode, D. J. \& Mullan, S. (1975). Pharmacologic treatment and evaluation of permanent experimental spinal cord trauma. Neurology, 25, 508 .

Donaghy, P. R. M. \& Numoto, M. (1969). Prognostic significance of sensory-evoked potentials in spinal cord injury. Proceedings of the 17th Veterans Administration Spinal Cord Injury Conference, p. 25I.

GilbIN, D. R. (1964). Somatosensory-evoked potentials in healthy subjects and in patients with lesions of the nervous system. Ann. N.Y. Acad. Sci. II2, 93.

MARTIN, S. H. \& BlOEDEL, J. R. (I973). Evaluation of experimental spinal cord injury using cortical-evoked potentials. F. Neurosurg. 39, 75 .

MeANS, E. D. \& ANDERSON, D. K. (I975). Histopathology of experimental spinal cord compression injury. Neuroscience Abstracts, I, I080.

Morin, F. (1955). A new spinal pathway for cutaneous impulses. Amer. F. Physiol. 183, 245.

Pudiphorn, T., Bantli, H., Bioedel, J. \& Chou, S. (I975). Effect of delayed local cooling on experimental spinal cord injury. $\mathcal{F}$. Neurosurg. 42, I 50.

Tarlov, I. M. (1957). Spinal Cord Compression: Mechanism of Paraplegia and Treatment. Charles C. Thomas, Springfield, Ill. $15 / 2-E$ 